\title{
Inflammatory Leukocytic Recruitment and Diffuse Neuronal Degeneration Are Separate Pathological Processes Resulting from Traumatic Brain Injury
}

\author{
Holly D. Soares, ${ }^{1}$ Ramona R. Hicks, ${ }^{2}$ Douglas Smith, ${ }^{3}$ and Tracy K. McIntosh ${ }^{3}$ \\ ${ }^{1}$ Department of Developmental Biology, SJCRH, Memphis, Tennessee 38101-0318, 2Division of Physical Therapy, \\ University of Kentucky, Lexington, Kentucky 40536-0079, and 'Division of Neurosurgery, University of Pennsylvania, \\ Philadelphia, Pennsylvania 19104
}

\begin{abstract}
The present study characterized whether inflammatory leukocytic infiltration is temporally and regionally correlated with neuronal degeneration and/or blood brain barrier (BBB) breakdown resulting from traumatic brain injury. Adult rats were sacrificed at $5 \mathrm{~min}, 2,4,12,24$, and $72 \mathrm{hr}$ after lateral fluid percussion brain injury. BBB breakdown, neuronal degeneration and leukocyte infiltration were assessed using immunocytochemistry, silver impregnation and toluidine blue and eosin staining. BBB breakdown and neuronal degeneration occurred concomitantly in injured cortex, hippocampus, and along the dorsolateral quadrant of the diencephalon. However, neuronal degeneration within deep diencephalic structures transpired in the absence of IgG extravasation. Neutrophils were observed only in regions exhibiting BBB damage and were first apparent in injured cortex and hippocampus between 2-12 hr posttrauma lining the vasculature and filling subarachnoid/subdural spaces. Neutrophils then migrated from damaged vasculature into traumatized cortical and hippocampal parenchyma by $24 \mathrm{hr}$ after lateral fluid percussion injury. Macrophages were also observed withln cortical parenchyma at $24 \mathrm{hr}$ and completely filled the cortical lesion site by $72 \mathrm{hr}$ after injury. Macrophages were not as abundant throughout hippocampal parenchyma and were found only in hippocampal regions exhibiting focal hemorrhage at $\mathbf{7 2} \mathbf{~ h r}$. Finally, neutrophils did not migrate to deep diencephalic structures that showed no BBB damage despite extensive neuronal degeneration. Indeed, lateral fluid percussion elicits inflammatory leukocytic recruitment only in regions experiencing concomitant BBB damage and neuronal degeneration. In summary, inflammatory leukocytic recruitment and diffuse neuronal degeneration are separate pathological processes resulting from traumatic brain injury.
\end{abstract}

[Key words: traumatic brain injury, inflammation, fluid

\footnotetext{
Receive Apr. 27, 1995; revised Aug. 14, 1995; accepted Aug, 21, 1995.

This study was supported, in part, by NIH Grants NS26818, NS08803, and a Merit Review grant from the Veterans Administration. Many thanks to Dr. Fujiro Sendo from the Department of Immunology and Parasitology, Yamagata University School of Medicine-Japan for his generous gift of the RP-1 antibody. Special thanks to Brain Perry and Drs. D. Kent Morest, Elisa Barbarese, Marion Frank, Gerald Maxwell, and William Shoemaker for help in preparations of the manuscript.

Correspondence should be addressed to Holly Soares, Department of Developmental Biology, St. Jude Children's IIospital, 322 North Lauderdale, Memphis, TN 38101-0318.

Copyright (C) 1995 Society for Neuroscience 0270-6474/95/158223-11\$05.00/0
}

percussion, leukocytes, neuronal degeneration, RP-1, neutrophils, macrophages, rat]

Although inflammatory leukocytes have long been implicated as pathological mediators in myocardial ischemic and pulmonary damage (Tate and Repine, 1983; Lucchesi and Mullane, 1986), the involvement of inflammatory cascades in CNS trauma are poorly understood. It is known that both neutrophils and macrophages appear in damaged brain following ibotenic acid injections (Coffey et al., 1990), intracerebral stab injury (Persson, 1976; Giulian et al., 1989; Moreno-Flores et al., 1993), spinal cord weight drop or compression (Means and Anderson, 1983; Holtz et al., 1990; Xu et al., 1990; Blight, 1992), spinal cord dorsal hemisection (Dusart and Schwab, 1994), brain weight drop contusion (Kochanek et al., 1990; Schoettle et al., 1990; Biagas et al., 1992; Clark et al., 1994), middle cerebral arterial occlusion (Barone et al., 1991; del Zoppo et al., 1991; Garcia et al., 1994; Matsuo et al., 1994), carotid air embolism (Hallenbeck et al., 1986) and after combined cryogenic brain injury/ hemorrhagic shock (Zhuang et al., 1993). However, it is not clear whether inflammatory leukocytes significantly contribute to CNS neuropathological damage.

Recent studies have suggested a pathological role for leukocytes during CNS injury. Clark et al. (1991a,b) described improvement in neurological deficits if antibodies capable of blocking neutrophil adhesion and transendothelial migration were administered prior to spinal cord ischemia. Matsuo et al. (1994) reported neutrophil depletion significantly attenuated edema formation and infarct size following middle cerebral arterial occlusion. Finally, treatment of rabbits with antiserum to neutrophils improved cerebral blood flow, infarct size, and ICP 4 hours after cerebral embolism (Bednar et al., 1991). Neutrophils hypothetically augment pathological processes by (1) secreting lysosomal enzymes, (2) releasing free radicals, (3) decreasing blood flow by direct physical microvascular occlusion, and (4) increasing vascular permeability (Harlan, 1985; Lucchesi and Mullane, 1986; Kochanek and Hallenbeck, 1992). In addition, activated macrophages may actually release a variety of cytokines known to exhibit both neurotrophic and neurotoxic properties (Lindholm et al., 1987; Hama et al., 1989; David et al., 1990; Mori et al., 1990; Taupin et al., 1993; Ott et al., 1994). Thus, neutrophils and macrophages may greatly influence pathological sequelae of traumatic brain injury.

Few studies have examined inflammatory events resulting from traumatic CNS damage. To further examine the role of 
inflammatory leukocytes in traumatic brain injury, the present study employed lateral fluid percussion in rats to elicit a clinically relevant form of brain trauma. The lateral fluid percussion brain injury model in the rat has been extensively characterized (Dixon et al., 1987; Vink et al., 1988; Cortez et al., 1989; McIntosh et al., 1989; Hovda et al., 1991; Smith et al., 1991; Yamakami and McIntosh, 1991; Yoshino et al., 1991; Lowenstein et al., 1992; Soares et al., 1992; Hicks et al., 1993; Dietrich et al., 1994) and reproduces much of the pathophysiology associated with human closed head injuries such as focal cortical contusion, blood brain barrier (BBB) breakdown and diffuse neuronal degeneration (Cortez et al., 1989; Dietrich et al., 1994; Hicks et al., 1995). However, it is not clear whether the pathological events transpiring during traumatic brain injury are also associated with inflammatory leukocytic recruitment.

In the present study, lateral fluid percussion was employed to characterize the spatiotemporal patterns of neutrophils and macrophages within contused brain. Our results demonstrate that inflammatory leukocytic recruitment is a significant neuropathological component of experimental traumatic brain injury. Interestingly, inflammatory leukocytes were localized only in regions exhibiting blood brain barrier (BBB) damage and not in diencephalic regions showing extensive neuronal degeneration without concomitant BBB injury. Thus, diffuse neuronal degeneration can transpire in the absence of inflammatory leukocytic recruitment and these two pathological processes appear to be distinct events resulting from traumatic brain injury.

\section{Materials and Methods}

\section{Animal surgery}

All protocols used in these studies were approved by the Animal Re search Committee at the University of Pennsylvania (IACUC), and were in accordance with guidelines set by the National Institutes of Health for the humane treatment of animals. Male albino Sprague-Dawley rats (350-400 gm; $n=36$ ) were anesthetized with $60 \mathrm{mg} / \mathrm{kg}$ sodium pentobarbital administered intraperitoneally. Prior to the initial scalp incision, rats received subcutaneous scalp injections of $1 \%$ lidocaine hydrochloride. Anesthetized animals were placed into a stereotaxic frame and a midline incision made to expose the skull. A stainless steel screw was secured to the skull over left anterior cortex as an anchor for the Luer-Lok connector. A $5 \mathrm{~mm}$ diameter craniotomy, centered between bregma, lambda, and the sagittal suture, was drilled over left parietal cortex leaving the dura intact. Ninety minutes following the initial anesthetic bolus, the anesthetized animals were then attached to the fluid percussion injury device via the female Luer-Lok connector and subjected to moderate contusive brain injury (2.3-2.4 atmospheres; $n=$ 30 ). Sham control animals underwent surgical procedure, but did not receive any injury $(n=6)$. Anesthetized animals were kept on a heating pad both prior and following injury to ensure normothermic temperatures were maintained (Okiyama et al., 1994). This model of fluid percussion has been previously described in detail (McIntosh et al., 1989).

\section{Tissue preparation}

At $5 \mathrm{~min}(n=7), 2 \mathrm{hr}(n=6), 4 \mathrm{hr}(n=4), 12 \mathrm{hr}(n=4), 24 \mathrm{hr}(n$ $=7)$, and $72 \mathrm{hr}(n=4)$ after injury, animals were reanesthetized with $200 \mathrm{mg} / \mathrm{kg}$ sodium pentobarbital intraperitoneally and transcardially perfused with $100 \mathrm{ml} 0.9 \%$ heparinized saline followed by $400 \mathrm{ml} 4 \%$ paraformaldehyde in $0.1 \mathrm{M}$ phosphate buffer $\mathrm{pH} 7.6$. Following perfusion, brains were removed and postfixed an additional $4 \mathrm{hr}$ at $4^{\circ} \mathrm{C}$, then transferred to $0.1 \mathrm{M}$ phosphate buffer; $35 \mu \mathrm{m}$ vibratome or $20 \mu \mathrm{m}$ cryostat sections were cul and Inounted onto gelatin coated slides. Adjacent alternate sections were either stained with toluidine blue and eosin, impregnated with silver, or immunocytochemically processed for the detection of extravasated $\operatorname{lgG}$ and neutrophilic/macrophagic antigens.

\section{Histological stains}

Toluidine blue and eosin. Sections were cleared in Xylene, rehydrated, and stained for $30 \mathrm{sec}$ in $0.05 \%$ toluidine blue in acetate buffer $\mathrm{pH} 4.4$
They were then rinsed in $\mathrm{ddH}_{2} \mathrm{O}$, and immersed in $0.05 \%$ eosin $\mathrm{Y}$ in $\mathrm{ddH}_{2} \mathrm{O}$ for 2 min. Sections were then dehydrated and coverslipped using Permount.

Silver impregnation for degenerating neurons (Gallyas et al., 1980; Nadler and Evenson, 1983). Sections were rinsed in glycerol/ddd $\mathrm{H}_{2} \mathrm{O} 3$ $\times 5 \mathrm{~min}$, and then pretreated $2 \times 5 \mathrm{~min}$ in $4.5 \%$ sodium hydroxide and $0.6 \%$ ammonium nitrate. Sections were then impregnated for $10-15 \mathrm{~min}$ in $5.4 \%$ sodium hydroxide, $6.4 \%$ ammonium nitrate, and $0.3 \%$ silver nitrate. Sections were then washed $3 \times 2$ min in $0.012 \%$ ammonium nitrate, $95 \%$ ethanol, and $0.5 \%$ anhydrous sodium carbonate. Silver precipitates on sections were developed for $1-2 \mathrm{~min}$ in $0.012 \%$ ammonium nitrated, $0.55 \%$ formalin, $95 \%$ ethanol, and $0.5 \%$ anhydrous citric acid. Sections were then washed $5 \times 5 \mathrm{~min}$ in $0.5 \%$ acetic acid in Tris- $\mathrm{HCl}$ $0.05 \mathrm{M} \mathrm{pH} \mathrm{7.4,} \mathrm{dried,} \mathrm{and} \mathrm{coverslipped.}$

IgG immunocytochemistry. Free floating vibratome sections or slide mounted cryostat sections were blocked for $1 \mathrm{hr}$ with $10 \%$ normal goat serum (NGS) and $0.3 \%$ Triton-X in $0.05 \mathrm{M}$ Tris- $\mathrm{HCl} \mathrm{pH} \mathrm{7.6.} \mathrm{Sections}$ were then rinsed in $2 \%$ NGS and incubated with biotinylated goat antirat IgG $(1: 50) 12-24 \mathrm{hr}$ at $4^{\circ} \mathrm{C}$. Controls included incubation with nonimmune biotinylated goat immunoglobulins and preadsorbed antibodies. All antibodies were obtained commercially from Accurate. Sections were then rinsed with $2 \%$ NGS/Tris $4 \times 15 \mathrm{~min}$, and then incubated for $2-4 \mathrm{hr}$ in FITC-streptavidin (Accurate 1:1000) in 2\% NGS. Following $3 \times 10$ min rinses, sections were mounted onto gelatin coated slides and coverslipped with a $2.5 \% \mathrm{DABCO}$ (Sigma)/glycerol solution.

Neutrophil and macrophage immunocytochemistry. Ten micrometer cryostat sections were blocked with $5 \%$ normal goat serum in $0.1 \mathrm{M}$ phosphate buffer $\mathrm{pH} 7.4$ for $30 \mathrm{~min}$ and then incubated overnight with either a monoclonal antibody for neutrophils or macrophages. The neutrophil-specific antibody RP-1 (Gotoh et al., 1986) was a generous gift from Dr. Fujiro Sendo (Yamagata University School of Medicine, Japan) and was used at a 1:500 dilution. The EDI and OX-42 (which recognizes the $\mathrm{CD} 11 \mathrm{~b}$ or complement receptor 3 antigen) monoclonal antibodies were utilized to detect macrophages/activated microglia (Serotec) and were used at a 1:100 and 1:5000 dilution, respectively. Sections were then rinsed $4 \times 10 \mathrm{~min}$ in buffer and incubated with FITC labeled goat-anti mouse IgG (Cappel; no cross-reaction to rat) for $6 \mathrm{hr}$. Finally, sections were again rinsed $4 \times 15 \mathrm{~min}$ in phosphate buffer and coverslipped with a $2.5 \%$ DABCO (Sigma)/glycerol solution.

\section{Histological analysis}

Adjacent sections from six coronal regions spaced throughout the anterior to posterior axis were analyzed for IgG extravasation (i.e., indicating BBB breakdown), the presence of neutrophils and macrophages, and neuronal degeneration (Fig. 1A). Using conventional histology, macrophages were identified as having a foamy cytoplasmic phenotype with an eccentrically placed ovoid/kidney shaped nuclei and large cell body diameters ranging from $20-40 \mu \mathrm{m}$ (Fig. $1 B$, arrow). The macrophage phenotype was confirmed with immunocytochemistry for macrophage antigens (Fig. $1 F$, arrow). Following toluidine blue and eosin staining, neutrophils exhibited faintly eosinophilic cytoplasmic granules, multilobed nuclei, and cell body diameters ranging from $10-15 \mu \mathrm{m}$ (Fig. $1 C$, arrow). The neutrophil phenotype within damaged tissue was confirmed using the RP-1 antibody which specifically recognizes neutrophils (Fig. $1 E$, arrowhead). Injured neurons appeared intensely argyrophilic with arborizations clearly visible during early stages of degeneration (Fig. $I D$, arrow). At later stages of degeneration (i.e., more than $24 \mathrm{hr}$ ), injured neuronal cell bodies remained intensely argyrophilic (Fig. 1, d1). Uninjured neurons appeared round with only the nucleoli showing slight argyrophilia (Fig. 1, d2). Neutrophils, macrophages, degenerating neurons and IgG extravasation were plotted onto spatiotemporal coronal maps utilizing an M1 Imaging Research image analysis system (Imaging Research Inc, Canada) connected to a Leitz Diaplan microscope. The symbol for each cell type represent cell numbers of more than five.

\section{Results}

\section{Experimental paradigm}

Figure 2 illustrates the gross pathology of lateral fluid percussion in rats. Twenty-four hours after trauma, a focal contusion forms within parietal and temporal cortices (Fig. 2A,B, arrows). Although lateral fluid percussion elicits extensive damage in hippocampal and diencephalic structures, only contused cortex ex- 
A

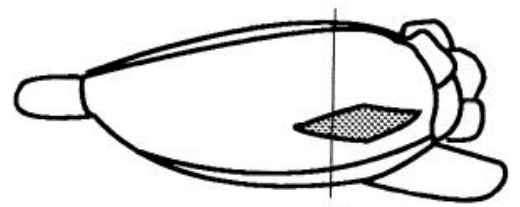

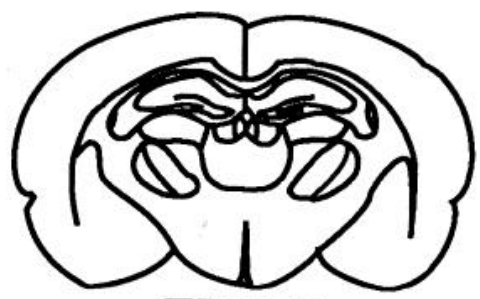

$T B$ \& $E$

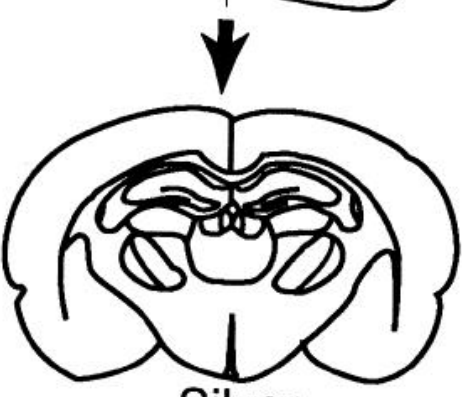

Silver
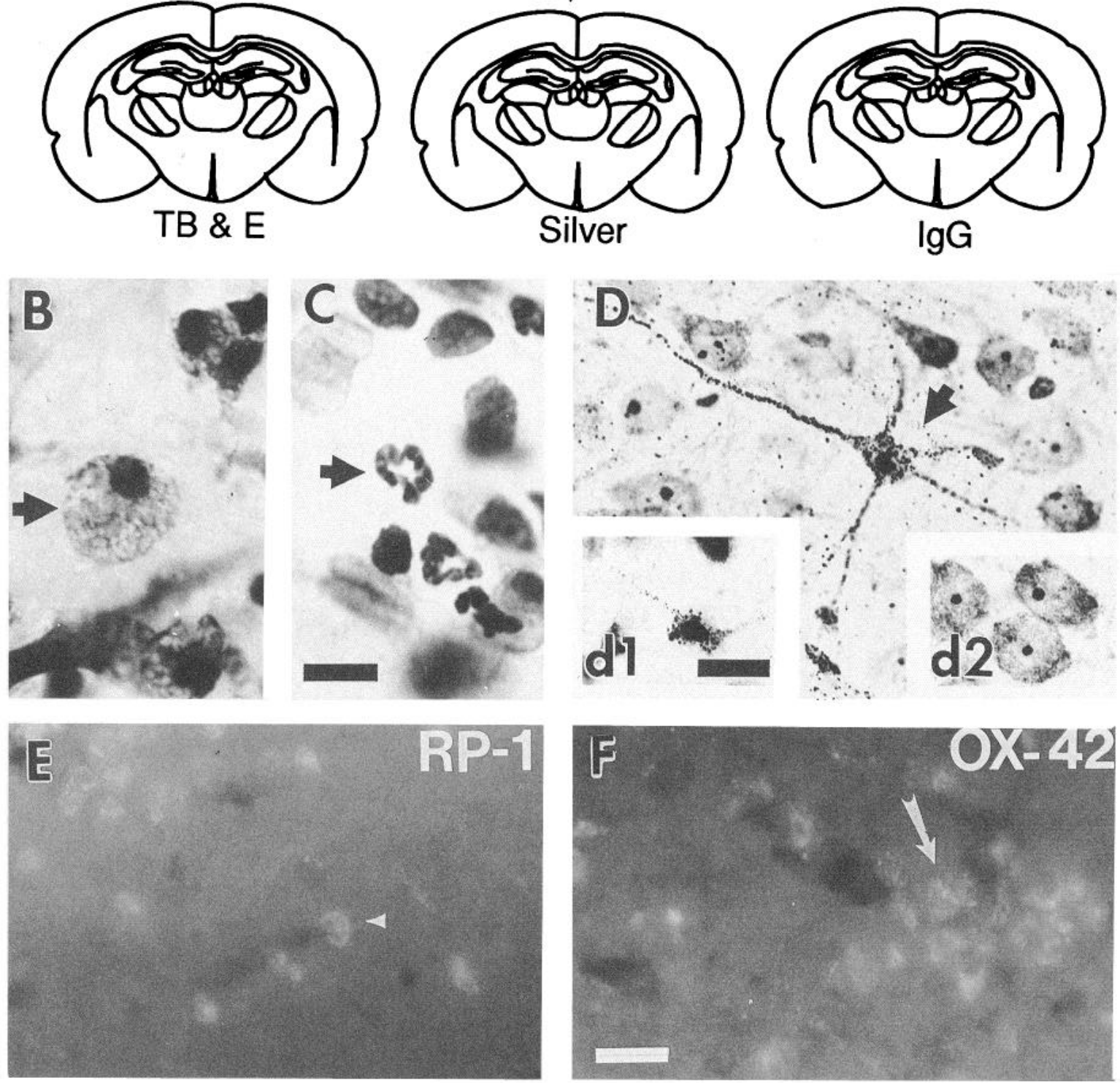

Figure 1. Experimental paradigm and gross pathology of lateral fluid percussion. A, Adjacent sections from injured brain were subjected to either $\mathrm{RP}-1, \mathrm{ED} 1$, or OX-42 immunocytochemistry or toluidine blue and eosin staining to detect leukocytes, silver impregnation to detect neuronal degeneration, and IgG immunocytochemistry to detect BBB breakdown. Individual cell types mapped in the present study are shown in $B-F$. Toluidine blue and eosin staining of a: $B$, foamy macrophage (arrow), and $C$, polymorphonuclear neutrophil (arrow). Silver impregnation of a: $D$, degenerating cortical neuron at $2 \mathrm{hr}$ after injury (arrow); $d 1$, Degenerating cortical neuron at $24 \mathrm{hr}$ after injury; $d 2$, Uninjured cortical neuron impregnated with silver. E, RP-1 immunocytochemistry of neutrophils within injured cortex at $12 \mathrm{hr}$ after trauma (arrowhead demarcates an RP-1 immunopositive cell). $F$, OX-42 immunocytochemistry of a large foamy macrophage (arrow) in injured cortex at 24 hr after injury. Scale bars: $C$, $15 \mu \mathrm{m}$ (for $B$ and $C$ ); $d 1,25 \mu \mathrm{m}$ (for $d l$ and $d 2$ ); $F, 30 \mu \mathrm{m}$ (for $E$ and $F$ ).

hibits profound cavitation by 4 weeks after injury (Fig. 2C,D, arrowheads).

\section{Leukocytes within contused brain}

Figure 3 illustrates the pattern of leukocytic infiltration within contused cortex following lateral fluid percussion brain injury in the rat. Under normal conditions, leukocytes do not fill the subarachnoid/subdural spaces (Fig. $3 A$ ) nor are they present in cortical parenchyma of a sham control brain (Fig. 3B). Leukocytes were not observed at $5 \mathrm{~min}$ after trauma (data not shown). However, between $2-4 \mathrm{hr}$ after injury, neutrophils filled subarachnoid/subdural spaces adjacent to contused cortex (Fig. $3 C$, ar- 

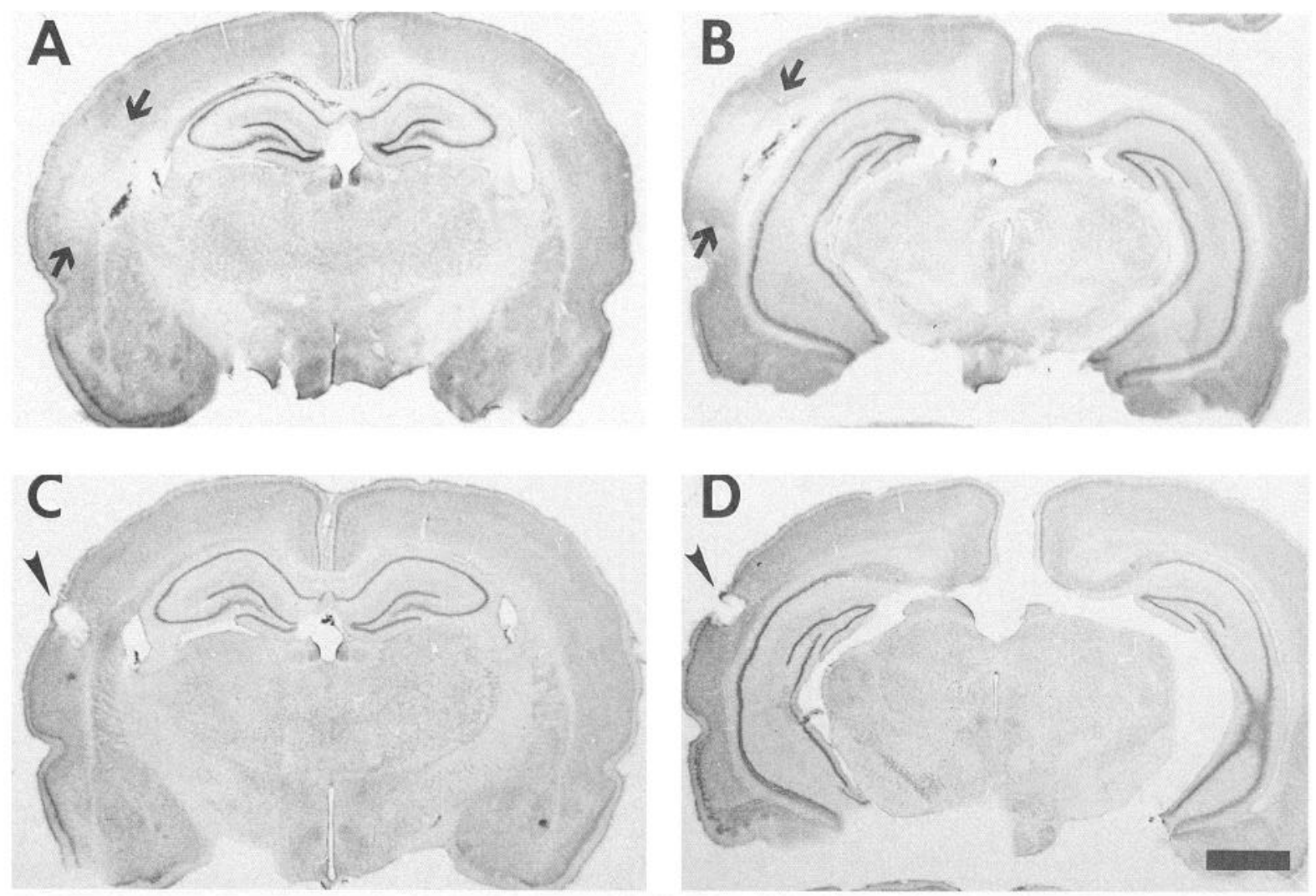

Figure 2. Gross pathology resulting from moderate levels of lateral fluid percussion brain injury in the rat. Moderate injury produces a focal contusion within parietal/temporal cortex $(A$ and $B$, arrows). By 4 weeks after injury, the original cortical lesion has formed a glial lined cavity $(C$ and $D$, arrowheads). Scale bar in $D, 2 \mathrm{~mm}$ (for $A-D$ ).

rows) and were evident lining large blood vessels of injured cortex at $4 \mathrm{hr}$ (Fig. $3 D$ and d, arrows). Neutrophils were not observed outside of blood vessels, nor where any neutrophils observed within contused cortical parenchyma at $4 \mathrm{hr}$ post injury. Monocytic cell types were also observed lining the cortical vasculature of injured cortex at 12 hours (data not shown). By $24 \mathrm{hr}$, neutrophils had progressed from damaged blood vessels into cortical parenchyma (Fig. $3 E$, small arrows) and the first foamy macrophages were observed (Fig. $3 E$, arrowhead). Parenchymal damage was extensive in cortex and, by $72 \mathrm{hr}$ after trauma, very few neurons remained and the contused cortical region was comprised primarily of foamy macrophages (Fig. $3 F$, arrowheads), blood vessels, monocytic cells, and megakaryocytes. Thus, inflammation is a significant pathological process within contused cortex following lateral fluid percussion brain injury.

\section{Leukocytes within contused subcortical structures}

Subcortical structures did not display the same distribution or temporal patterns of inflammatory leukocytic infiltration as did contused cortex. Figure 4 shows inflammatory leukocytes within the hippocampus and thalamus ipsilateral to the site of cortical trauma. Neutrophils were observed within subarachnoid spaces between hippocampus and dorsolateral thalamus (data not shown) and in large blood vessels of ipsilateral hippocampus between 2 and $12 \mathrm{hr}$ after trauma. Figure $4 A$ illustrates neutrophils lining an injured blood vessel within ipsilateral hippocampus at $12 \mathrm{hr}$ after lateral fluid percussion (arrows). At 12 and 24 hr after trauma, neutrophils were abundantly present throughout ipsilateral hippocampal parenchyma especially along ipsilateral dentate gyrus at $12 \mathrm{hr}$ (Fig. $4 B$, arrows) and around CA3. Although macrophages completely filled the contusion within injured cortex, macrophages did not completely fill hippocampal parenchyma at $72 \mathrm{hr}$ after fluid percussion brain injury. Indeed, macrophages were only observed within small hemorrhagic foci around the CA1, CA2, CA3, and dentate hippocampal regions at $72 \mathrm{hr}$ posttrauma (Fig. $4 C$, arrowheads). Thus, inflammatory leukocytic infiltration within ipsilateral hippocampus was dominated by neutrophils during the acute postinjury period while macrophages with foamy cytoplasmic phenotypes remained localized to small hemorrhagic foci.

Inflammatory leukocytic recruitment to thalamus and deep diencephalic structures appeared to be confined to left superficial dorsolateral nuclei. Neutrophils did not line the vasculature of diencephalic structures as observed in injured cortex and hippocampus during the acute postinjury period, nor did they accumulate within deep diencephalic parenchyma at any of the time points examined. Figure $4 D$ shows ipsilateral posterior thalamus at $24 \mathrm{hr}$ after injury. Despite extensive gliosis and neuronal degeneration, neutrophils were not observed in ipsilateral posterior thalamus at either 24 (Fig. $4 D$ ) or $72 \mathrm{hr}$ after injury (see also Fig. 5). A few cells in the dorsolateral thalamus were ED1 and OX-42 positive and tended to exhibit morphological characteristics of microglia such as ramified processes (data not shown). Nevertheless, neutrophils were not localized in diencephalic structures and the classical sequence of acute inflammatory leukocytic recruitment (i.e., neutrophils followed by macrophages) occurred only within contused cortex and hippocampus and not within deep diencephalic areas. 

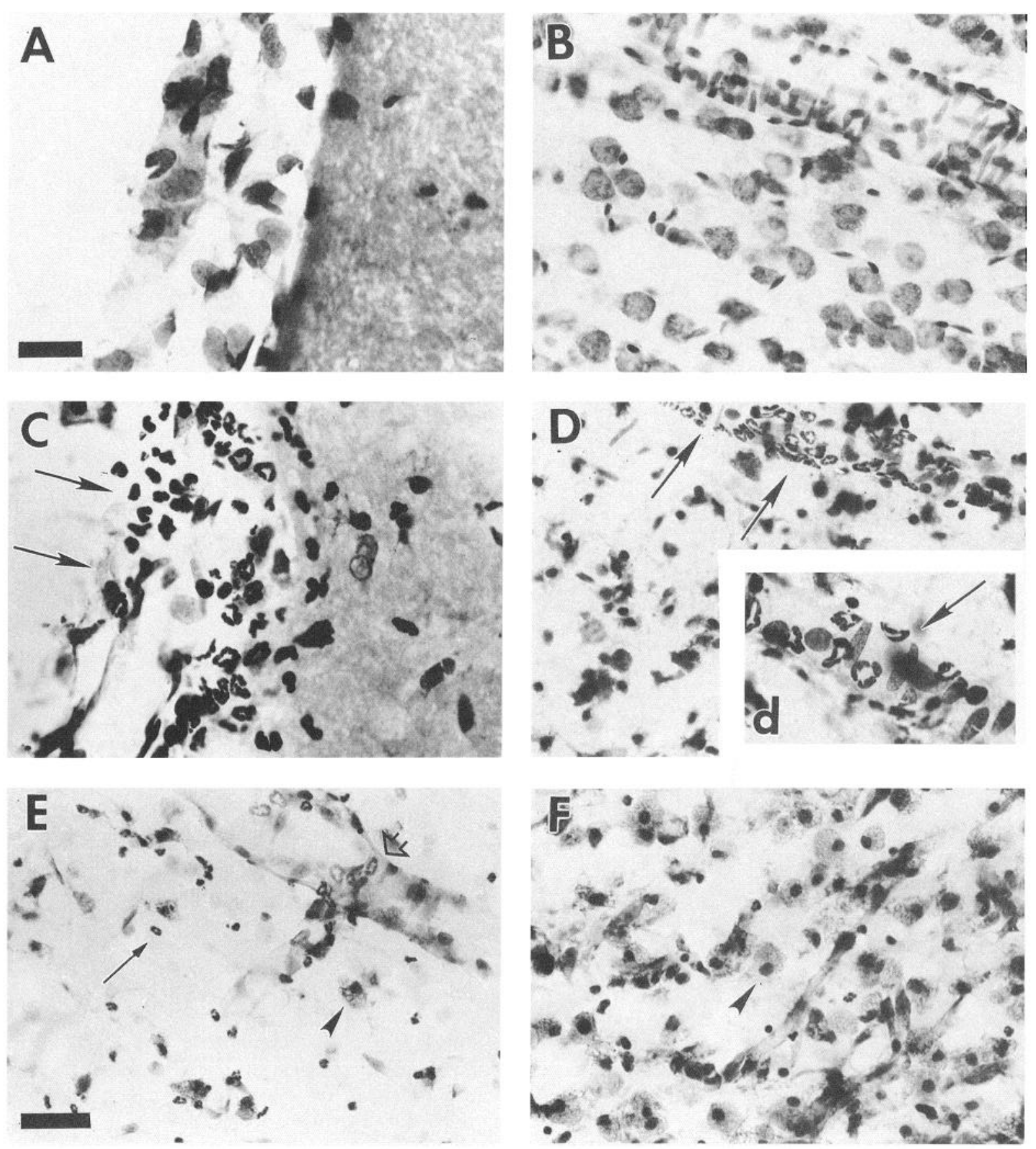

Figure 3. Inflammatory leukocytic recruitment within contused cortex. A, Subarachnoid/subdural space adjacent to parietal cortex of sham control brain. $B$, Cortical parenchyma and large blood vessel within sham control brain. Note the absence of neutrophils or activated macrophages within control sham cortex. At $4 \mathrm{hr}$ after injury, neutrophils appeared within subdural/subarachnoid spaces next to contused cortex ( $C$ arrows), and lined large blood vessels within contused cortex ( $D$ arrows). $d$, Higher magnification of neutrophils lining blood vessel. $E, 24 \mathrm{hr}$ after injury, neutrophils migrated from vasculature (open arrow) into injured cortical parenchyma (small arrow). Foamy macrophages were also present (arrowhead). $F$, $72 \mathrm{hr}$ after injury, the contused cortical parenchyma was dominated by foamy macrophages (arrowhead), monocytic cells, and megakaryocytes. Scale bars: $A, 25 \mu \mathrm{m}$ (for $A$ and $C$ ); $E, 30 \mu \mathrm{m}$ (for $B, D, E, F$ ).

\section{Spatiotemporal leukocytic patterns versus $\operatorname{Ig} G$ extravasation}

Figure 5 summarizes the temporal and regional patterns of leukocyte infiltration to patterns of blood brain barrier damage as evidenced by IgG extravasation at 4,24 , and $72 \mathrm{hr}$ after contusion. In sham control brains, endogenous IgG was normally present within regions lacking a functional BBB. These regions included the area postrema, subfornical organ, median eminence, choroid plexus, and the organum vasculosum of the lamina ter- minalis (data not shown). In addition, IgG was also observed in subarachnoid spaces and pial surfaces but did not extend into the parenchyma of brain regions possessing an intact BBB in sham brains (data not shown). However, at $4 \mathrm{hr}$ after lateral fluid percussion injury, IgG extravasation was localized within contused cortex; hippocampal CA2, CA3 pyramidal regions; hippocampal hilus of the dentate gyrus; and along the dorsolateral edge of the diencephalon (Fig. 5, shaded regions). Large blood 

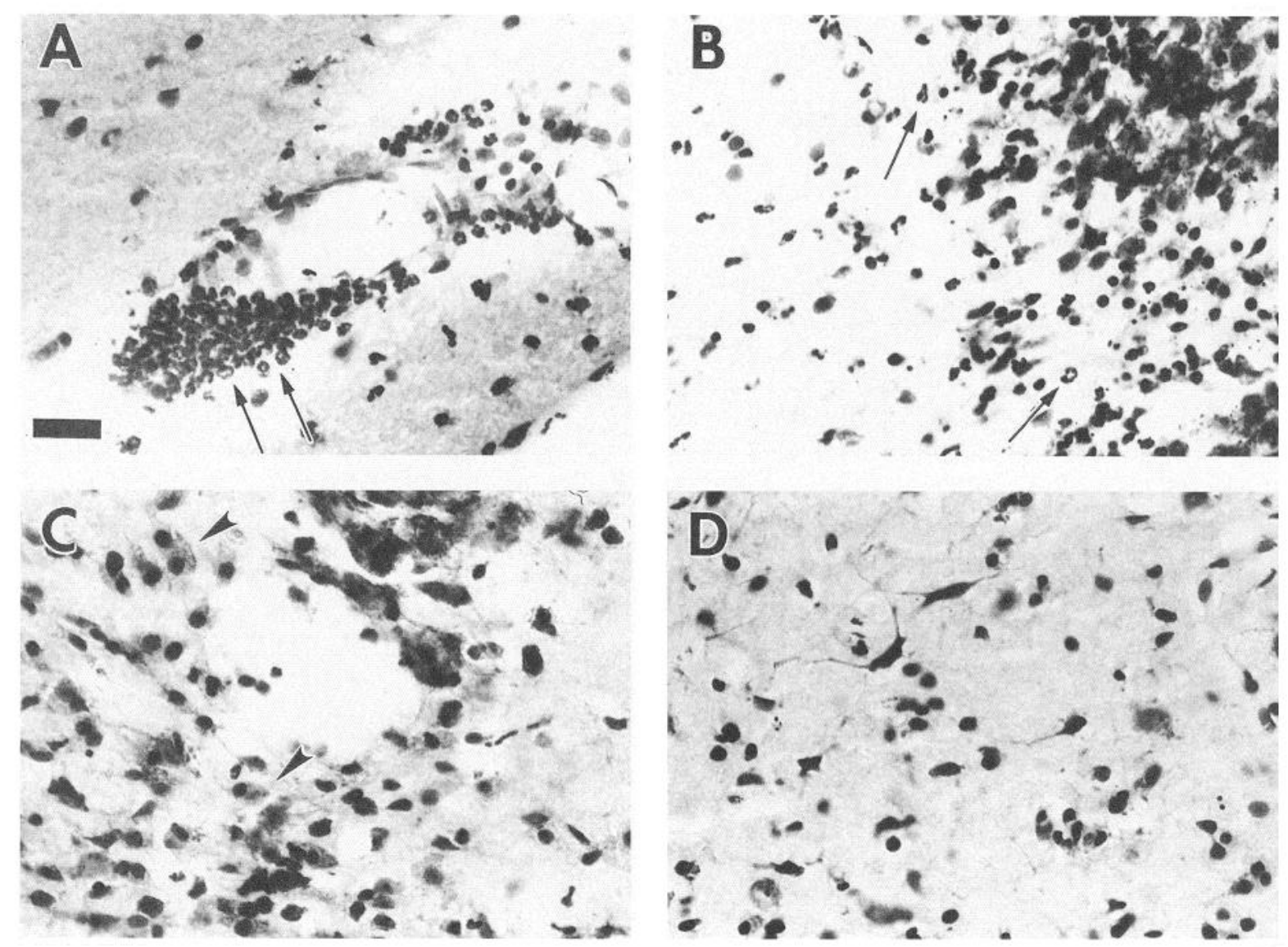

Figure 4. Leukocytes in contused hippocampus and thalamus after lateral fluid percussion. A, Neutrophils lined large blood vessels within contused hippocampus at $12 \mathrm{hr}$ after injury (arrows). B, Neutrophils were also present within hippocampal parenchyma surrounding dentate gyrus at $12 \mathrm{hr}$ after injury (arrows). C, A few foamy macrophages were found within small hemorrhagic foci of CA3 at $72 \mathrm{hr}$ after trauma (arrowhead). D, Gliosis and neuronal degeneration in the posterior nucleus of thalamus $24 \mathrm{hr}$ after injury. Note the absence of neutrophils or foamy macrophages. Scale bar in $A, 25 \mu \mathrm{m}$ (for $A-D$ ).

vessels within ipsilateral hippocampus also demonstrated IgG extravasation at 4 hours after trauma (data not shown). By 24 hr, IgG extravasation had spread throughout contused cortical and injured hippocampal parenchyma (Fig. 5, shaded region). Diencephalic IgG extravasation remained confined to the dorsolateral quadrant. In addition, small focal hemorrhagic regions were often observed in the substantia nigra, posterior pons and brainstem (data not shown). Neutrophils, as identified using RP-1 immunocytochemistry and conventional histology, first appeared in cortical and hippocampal blood vessels at $4 \mathrm{hr}$ (Fig. 5, squares) and were later observed (Fig. 5, asterisk) in hippocampal and cortical parenchymal regions 24-72 hr. Large foamy macrophages (Fig. 5, solid circles), as identified using immunocytochemistry and conventional histology, were observed within contused cortical parenchyma at $24 \mathrm{hr}$ and eventually filled the original cortical contusion by $72 \mathrm{hr}$. However, such a dramatic accumulation of large foamy macrophages was not observed in either hippocampal or diencephalic structures. Within the injured hippocampus and diencephalon, large foamy macrophages remained confined to small hemorrhagic foci. Neutrophils and monocytic cell types did not appear to line diencephalic vasculature. In addition, neutrophils did not appear to migrate throughout diencephalic parenchyma except in regions exhibiting IgG extravasation and/or hemorrhage. Thus, acute inflammatory leukocytic infiltration was confined to regions show- ing concomitant BBB damage as evidenced by IgG extravasation.

\section{IgG extravasation versus neuronal degeneration}

Figure 6 compares the temporal and regional patterns of $\mathrm{IgG}$ extravasation to those of neuronal degeneration resulting from lateral fluid percussion brain injury in the rat. Sham controls exhibited no agryophilic neurons and endogenous IgG was confined to regions lacking a functional BBB (data not shown). Between 2-24 hr post injury, argyrophilic neurons and extravasated IgG were both observed within parietal, temporal, and retrosplenial cortices; and in hippocampal CA2, CA3, dentate gyrus, and dentate hilus (Fig. 6). Although cortical IgG extravasation persisted throughout the $72 \mathrm{hr}$ observation period, most of the cortical neurons had degenerated by $72 \mathrm{hr}$. Interestingly, neuronal degeneration within the hippocampus was localized to specific regions despite widespread IgG extravasation (Fig. 6). Ipsilateral thalamic degeneration predominated throughout dorsal, lateral posterior, ventral posterior lateral, ventral posterior medial, and centromedial nuclei at 4,24 , and $72 \mathrm{hr}$ postinjury (Fig. $6)$. Very few degenerating neurons were observed within the lateral geniculate, although the medial geniculate possessed numerous argyrophilic neurons at 4,24 , and $72 \mathrm{hr}$ after injury. A few degenerating neurons were observed within the ipsilateral superficial gray and in the optic nerve layer of the superior col- 

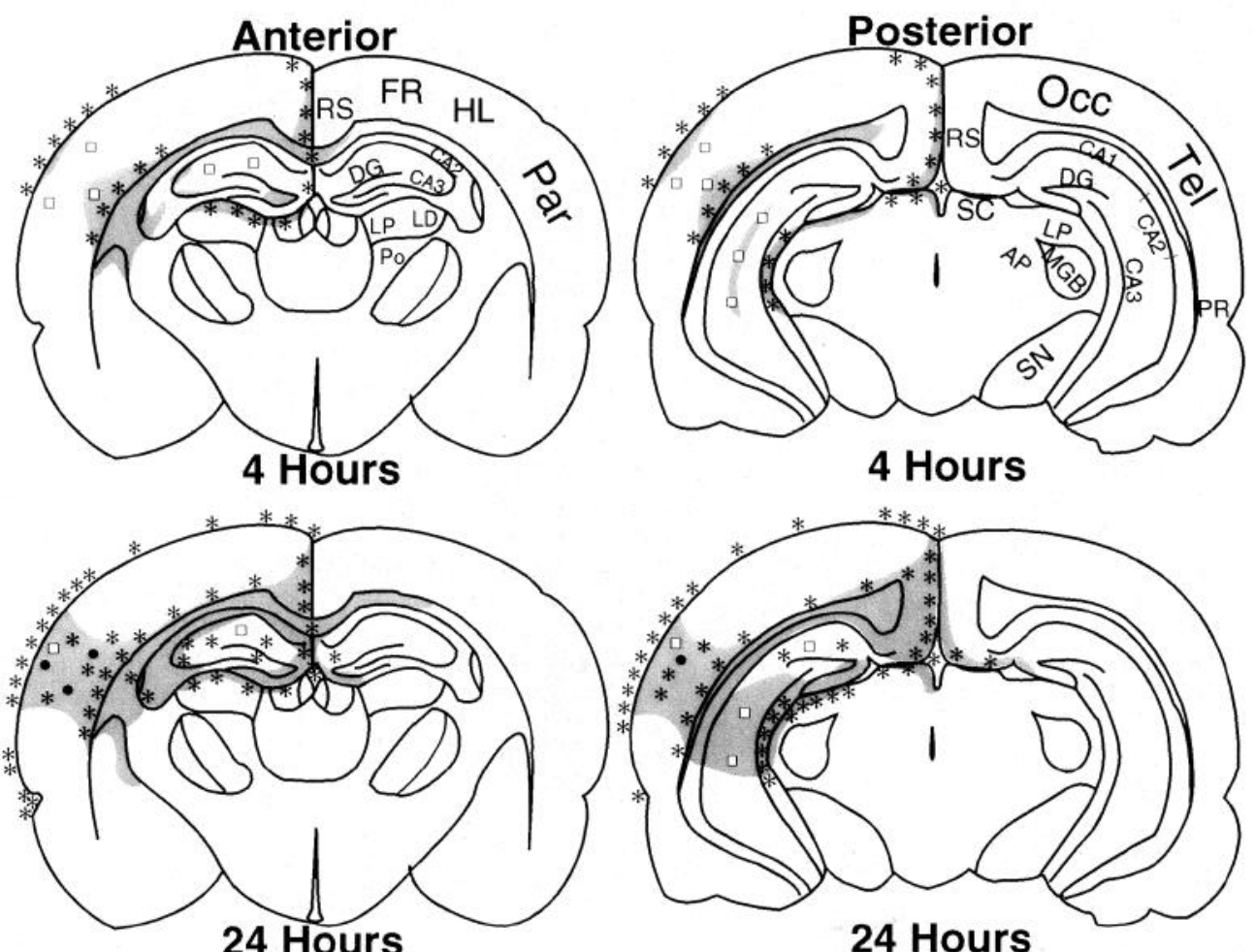

Figure 5. Spatiotemporal pattern of leukocytes versus IgG extravasation at 4,24 , and $72 \mathrm{hr}$ after trauma. Neutrophilic recruitment and macrophages appear in regions exhibiting BBB breakdown. Square, Neutrophils in blood vessel; asterisk, neutrophil in parenchyma; solid circle, foamy macrophages. Shaded regions, IgG extravasation. $A P$, anterior pretectal; $C L$, central lateral; $D G$, dentate gyrus; $D L G$, dorsal lateral geniculate; $F R$, frontal cortex; $H L$, hindlimb cortex; $L D$, lateral dorsal thalamus; $L P$, lateral posterior thalamus; $M G B$, medial geniculate body; $O c c$, occipital cortex; Par, parietal cortex; Po, posterior thalamus; $P R$, perirhinal cortex; $R S V$, retrosplenial cortex; $S C$, superior colliculus; $S N$, substantia nigra; Tel,

72 Hours

- Neutrophils in Blood Vessel
72 Hours
* - Neutrophil

\section{2}

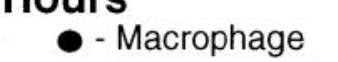
temporal cortex; $V P L$, ventral posterior

temporal cortex; $V P L$, ventral posterior
lateral; $V P M$, ventral posterior medial. liculus at all the time points examined. Interestingly, degeneration within traumatically injured diencephalic structures occurred over more prolonged periods than degeneration within ipsilateral cortex or hippocampus. Figure 6 shows that diffuse neuronal degeneration within the diencephalon occurred without accompanying $\mathrm{IgG}$ extravasation. Thus, lateral fluid percussion elicits extensive acute inflammatory leukocytic infiltration only in regions exhibiting blood brain barrier damage and not in degenerating diencephalic regions which maintain a relatively intact blood brain barrier.

\section{Discussion}

The present study demonstrates that traumatic brain injury is associated with acute inflammatory pathology. Following lateral fluid percussion in the rat, neutrophils line injured vasculature within $2-4 \mathrm{hr}$ in brain regions exhibiting BBB breakdown and infiltrate injured parenchyma by $24-72 \mathrm{hr}$ after trauma. Macrophages are most abundant between $12-72 \mathrm{hr}$ and predominate in the contused cortical region which eventually forms a gliallined cavity. Interestingly, lateral fluid percussion in the rat also produces diffuse neuronal degeneration within deep diencephalic structures which is not associated with IgG extravasation. Although diencephalic degeneration is extensive, acute inflammatory leukocytic recruitment characterized by both neutrophils and macrophages is not robust in this region. Thus, acute inflammatory pathology following lateral fluid percussion injury occurs only in traumatized regions exhibiting concomitant BBB damage and neuronal degeneration. These data suggest that diffuse neuronal degeneration and acute inflammatory leukocytic recruitment are distinct pathological processes that result from traumatic brain injury.

Under normal circumstances, endogenous serum proteins can only be detected in brain regions lacking a functional BBB such as the circumventricular organs and subarachnoid spaces (Broadwell and Sofroniew, 1994). Serum proteins cannot traverse an intact $\mathrm{BBB}$, and as a result, endogenous serum protein extravasation has served as a useful index for accessing BBB function (Broadwell et al., 1992, 1994). If sufficient care is taken during perfusion and immunocytochemical procedures, then IgG extravasation into the parenchyma of brain regions known to pos- 

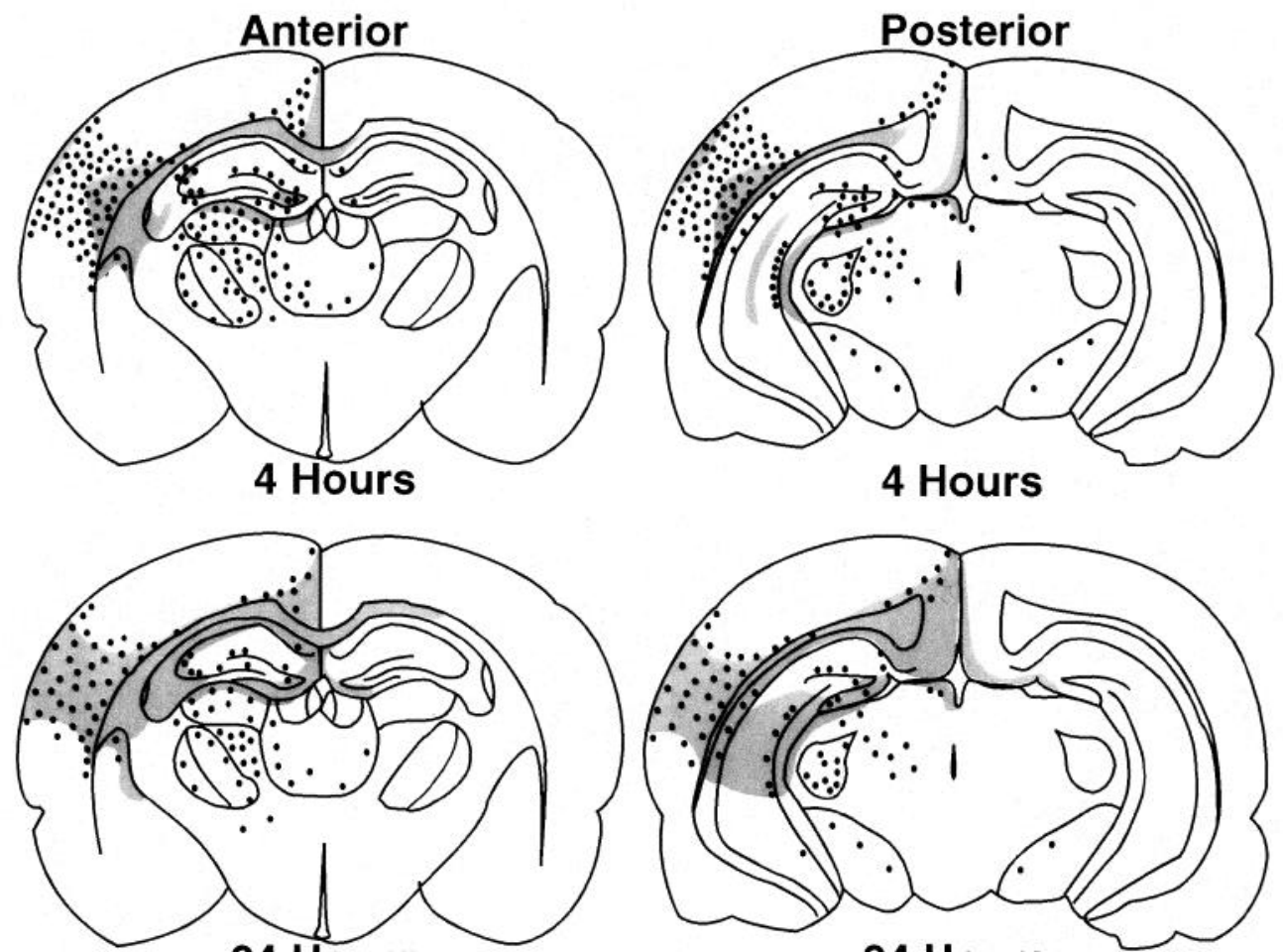

24 Hours

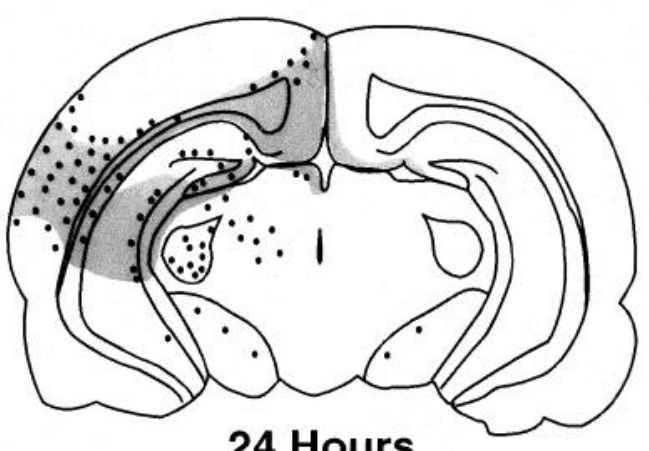

24 Hours

Figure 6. $\operatorname{IgG}$ extravasation versus neuronal degeneration at 4,24 , and 72 $\mathrm{hr}$ after injury. Diffuse neuronal degeneration within diencephalic structures occurred in the absence of BBB breakdown. Solid circles, argyrophilic neurons. Shaded regions, IgG extravasation.

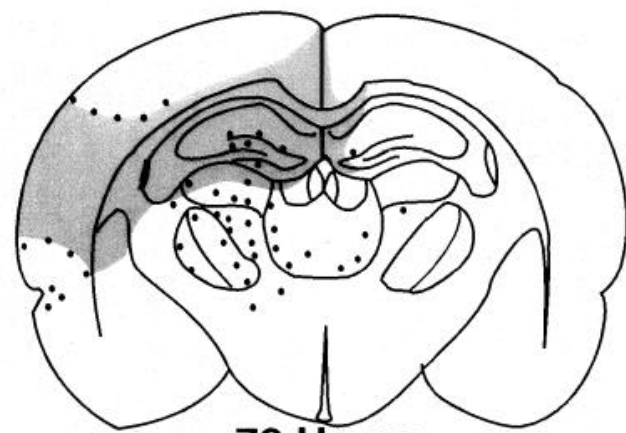

72 Hours

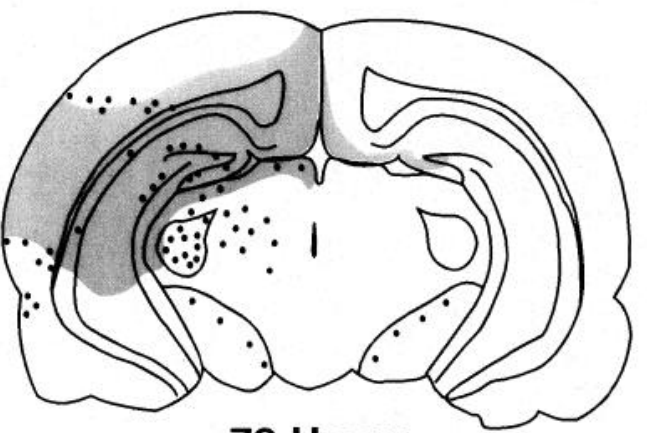

72 Hours sess a $\mathrm{BBB}$ is indicative of $\mathrm{BBB}$ dysfunction (Tanno et al., 1992a,b; Broadwell et al., 1994). Indeed, BBB breakdown following brain trauma, as evidenced by IgG or HRP extravasation, has been reported in other laboratories utilizing slightly different models of lateral fluid percussion in rats (Tanno et al., 1992a,b; Schmidt and Grady, 1993; Dietrich et al., 1994). Our data described endogenous IgG within sham controls only in brain regions deficient in a $\mathrm{BBB}$ which is in good agreement with Broadwell and Sofroniew (1994). Following lateral fluid percussion, however, IgG extravasation was widespread within the injured parenchyma of ipsilateral cortex, hippocampus, and dorsolateral thalamus. Indeed, similar patterns of BBB breakdown have also been reported in other laboratories utilizing lateral fluid percussion especially in injured cortical and hippocampal regions (Tanno et al., 1992a,b; Schmidt and Grady, 1993). In general, studies from the above mentioned laboratories showed that BBB damage within diencephalic structures was not as extensive as in ipsilateral cortex or hippocampus which is in good agreement with the present observations (Tanno et al., 1992a,b; Schmidt and Grady, 1993). Our data adds to the literature by demonstrating that the $\mathrm{BBB}$ damage resulting from lateral fluid percussion is also associated with an acute phase of neutrophilic infiltration followed by macrophagic activation. Thus, acute inflammatory mechanisms may profoundly influence secondary posttraumatic sequelae following brain trauma.

It is not clear why neutrophils were recruited only to regions exhibiting blood brain barrier breakdown. Previous studies have shown that injured endothelium can upregulate endogenous leukocytic adhesion molecules and release leukocytic chemotactic factors (Bowman et al., 1983; O'Brien et al., 1984; Harlan, 1985; Sloan et al., 1992; Arnould et al., 1993; Albelda et al., 1994; Ott et al., 1994). Current hypotheses suggest that leukocytes and endothelium directly bind to each other through either lectin-like adhesion molecules or, via integrin family receptors and immunoglobulin superfamily members (Kochanek and Hallenbeck, 1992; Sloan et al., 1992; Albelda et al., 1994). In fact, inflammatory pathological damage following either myocardial (Ma et al., 1991; Yamazaki et al., 1993), pulmonary (Horgan et al., 1990), or CNS ischemia (Clark et al., 1991a,b) can be attenuated if neutrophil adhesion to endothelium is inhibited using antibodies to $\beta_{2}$ integrin or CAM-like proteins. Therefore, it is entirely possible that injured endothelium upregulates neutrophil 
adhesion factors after brain trauma. Such a phenomena may perhaps explain why neutrophils were only observed in traumatically injured regions exhibiting blood brain barrier damage.

Neutrophils could greatly exacerbate the pathological sequelae of brain trauma by altering vascular permeability (Wedmore and Williams, 1981), contributing to oxidative damage (Tonnesen et al., 1988), inducing further neuronal damage via the secretion of lysosomal enzymes (Tonnesen et al., 1988), or by altering cerebral vascular blood flow. Indeed, Uhl et al. (1994) showed that acute inflammation resulting from weight drop brain injury could contribute to the observed level of cerebral blood flow (CBF) in injured brain regions especially in those regions which experienced increases in $\mathrm{CBF}$. In addition, polymorphonuclear leukocyte recruitment has been correlated with increased cerebral edema in a weight drop paradigm of brain contusion (Schoettle et al., 1990) and neutrophil depletion has been reported to attenuate increases in brain water content and decrease infarct size following middle cerebral arterial occlusion (Matsuo et al., 1994). It is intriguing to nute that the same regions exhibiting neutrophil infiltration in our model of fluid percussion do proceed to develop edema (Soares et al., 1992). Thus, neutrophils may contribute to edematous sequelae following lateral fluid percussion.

Acute inflammation is characterized by the early appearance of neutrophils followed by macrophages. The present study shows extensive recruitment of neutrophils to injured cortex, hippocampus, and dorsolateral thalamus, but not to deep diencephalic structures. Macrophages are identifiable after the ap pearance of neutrophils within injured cortex, hippocampus, and dorsolateral thalamus suggesting that acute inflammation does occur in these regions as a result of lateral fluid percussion. However, it is not clear whether macrophages are indeed recruited, or whether they arise from resident populations such as microglia. Our data is in good agreement with the work of $\mathrm{Ai}$ hara et al. (1995) which described the timecourse and localization of EDI and OX-42 immunopositive cells following fluid percussion injury. Infortunately, once microglia become activated, they express all macrophagic markers including EDI (Flaris et al., 1993; Ling and Wong, 1993) and it is not a trivial matter distinguishing recruited macrophages from activated microglia. Although it is likely that many of the macrophages within contused cortex were recruited, our results do not directly demonstrate that the macrophages we observed within injured brain regions actually originated from outside the CNS. Indeed, it is quite probable the macrophagic population consisted of both resident and recruited cells. Nevertheless, our data does demonstrate that neutrophils were recruited to some, but not all traumatically injured brain regions. Specifically, neutrophils were not observed in deep diencephalic structures. This is an important observation in that blood vessel damage is minimal within diencephalic structures despite extensive neuronal degeneration. Indeed, it would suggest that neutrophils may be responding more to vascular damage than to neuronal degeneration. Clearly, neutrophil recruitment and diffuse neuronal degeneration are separate events following lateral fluid percussion brain injury.

The most likely mechanism by which neutrophils and activated macrophages/microglia can alter the pathological milieu is probably through the secretion of soluble factors such as cytokines. For example, IL-6, IL-1, and tumor necrosis factor alpha $\left(T_{N F}-\alpha\right)$ levels increase and remain elevated in the brain following traumatic injury (Goodman et al., 1990; McClain et al., 1991; Taupin et al., 1993). Although IL-6 and IL-1 have been reported to exert neurotrophic effects in vitro (Lindholm et al., 1987; Hama et al., 1989), pathological events could be exacerbated through abnormal endothelial effects. Indeed, both IL-1 and TNF- $\alpha$ are capable of altering vascular permeability (Beynon et al., 1993; Burker-Gaffney and Kecnan, 1993) and these cytokines could exacerbate BBB breakdown and subsequent hrain edema formation. In addition, traumatic brain injury has been reported to elicit elevations in plasma levels of cytokines (McClain et al., 1991) which could, in turn, contribute to such systemic complications as stress-related mucosal disease and pulmonary edema experienced by many severely head injured patients (Ott et al., 1994). Thus, secretory factors from activated leukocytes within the brain or circulating systemically may profoundly contribute to secondary pathological cascades following traumatic brain injury.

In addition to inflammation and BBB breakdown, lateral fluid percussion produced extensive neuronal degeneration. Although neuronal degeneration within fluid percussion injured cortex and hippocampus was associated with BBB breakdown, the present study showed that much of the neuronal degeneration within regions of the diencephalon transpired in the absence of $\operatorname{IgG}$ extravasation. Neuronal degeneration without associated vascular damage has been observed in other experimental models of brain trauma (Povlishock, 1986; Povlishock et al., 1992) and may account for human head injuries which present as coma in the absence of mass lesions (Strich, 1956; Sahuquillo et al., 1989: Graham et al., 1993). It is interesting to note that, in our model, neutrophils appear only in contused brain regions experiencing BBB breakdown. Neutrophils did not infiltrate damaged regions failing to exhibit $\mathrm{IgG}$ extravasation despite extensive neuronal degeneration. Indeed, the present study suggests that diffuse diencephalic degeneration is a pathological process distinct from traumatically induced acute inflammatory leukocytic recruitment in the brain.

In conclusion, lateral fluid percussion elicits complex neuropathology involving both inflammatory cascades and diffuse neuronal degeneration. Leukocytes are known to act as pathogenic mediators in experimental model of myocardial and CNS ischemia (Lucchesi and Mullane, 1986; Kochanek and Hallenbeck, 1992) and may serve similar pathological functions following traumatic brain injury. In fact, a number of pharmacological agents which possess immunosuppressive characteristics have been reported to improve outcome following contusive CNS injuries (McIntosh, 1993; Okiyama et al., 1994). Furthermore, recent attempts at inhibiting leukocytic inflammatory processes through the blockage of cell adhesion molecules or by neutrophil depletion has shown promise in some models of ischemia (Albelda et al., 1994; Matsuo et al., 1994). Although the present study did not demonstrate a casual relationship between leukocyte recruitment and neuropathological events such as brain edema, it is intriguing that neutrophils were localized first along blood vessels within injured regions which go on to develop BBB breakdown. Clearly, further studies need to be pursued regarding the leukocytic contribution to traumatic brain injury. Our results do emphasize, however, that traumatic brain injuries may contain a diffuse degenerative component which can be quite distinct from leukocytic recruitment. Thus, separate pharmacological strategies may prove critical in the effective management of inflammatory sequelae and diffuse neuronal pathology resulting from traumatic brain injury. 


\section{References}

Aihara N, Hall JJ, Pitts LH, Fukuda K, Noble LJ (1995) Altered immunoexpression of microglia and macrophages after mild head injury. J Neurotrauma 12:53-63.

Albelda SM, Smith CW, Ward PA (1994) Adhesion molecules and inflammatory injury. FASEB J 8:504-512.

Arnould T, Michiels C, Remacle J (1993) Increased PMN adherence on endothelial cells after hypoxia: involvement of PAF CD18/ CD11b, and ICAM-1. Am J Physiol 264:C1102-C1110.

Barone FC, Hillegass LM, Price WJ, White RF, Lee EV, Feuerstein GZ, Sarau HM, Clark RK, Griswold DE (1991) Polymorphonuclear leukocyte infiltration into cerebral focal ischemic tissue: myeloperoxidase activity assay and histologic verification. J Neurosci Res 29: 336-345.

Bednar MM, Raymond S, McAuliffe T, Lodge PA, Gross CE (1991) The role of neutrophils and platelets in a rabbit model of thromboembolic stroke. Stroke 22:44-50.

Beynon HL, Haskard DO, Davies KA, Haroutunian R, Walport MJ (1993) Combinations of low concentrations of cytokines and acute agonists synergize in increasing the permeability of endothelial monolayers. Clin Exp Immunol 91:314-319.

Biagas KV, Uhl M, Schiding JK, Nemoto EM, Kochanek PM (1992) Assessment of posttraumatic polymorphonuclear leukocyte accumulation in rat brain using tissue myeloperoxidase assay and vinblastine treatment. J Neurotrauma 9:363-371.

Blight AR (1992) Macrophages and inflammatory damage in spinal cord injury. J Neurotrauma 9(Suppl 1):S83-S91.

Bowman CM, Butlcr EM, Rcpine JE (1983) Hyperoxia damages cultured endothelial cells causing increased neutrophil adherence. Am Reb Respir Dis 128:469-472.

Broadwell RD, Sofroniew MV (1994) Serum proteins bypass the blood-brain fluid barriers for extracellular entry to the central nervous system. Exp Neurol 120:245-263.

Broadwell RD, Baker BJ, Ebert PS, Hickey WF, Villegas J (1992) Intracerebral grafting of solid tissues and cell suspensions: the bloodbrain barrier and host immune response. Prog Brain Res 91:95-102.

Broadwell RD, Baker BJ, Ebert PS, Hickey WF (1994) Allografts of CNS tissue possess a blood-brain barrier. III. Neuropathological, methodological, and immunological considerations. Microse Res Tech 27:471-494.

Burker-Gaffney A, Keenan A (1993) Modulation of human endothelial cell pcrmeability by combinations of the cytokines interleukin- 1 alpha/beta, tumor necrosis factor-alpha and interferon-gamma. Immunopharmacology 25:1-9.

Clark RSB, Schiding JK, Kaczorowski SL, Marion DW, Kochanek PM (1994) Neutrophil accumulation after traumatic brain injury in rats: comparison of weight drop and controlled cortical impact models. J Neurotrauma 11:499-506.

Clark WM, Madden KP, Rothlein R, Zivin JA (1991) Reduction of central nervous system ischemic injury by monoclonal antibody to intercellular adhesion molecule. J Neurosurg 75:623-627.

Clark WM, Madden KP, Rothlein R, Zivin JA (1991) Reduction of central nervous system ischemic injury in rabbits using leukocyte adhesion antibody treatment. Stroke 22:877-883.

Coffey PJ, Perry VH, Rawlins JNP (1990) An investigation into the early stages of the inflammatory response following ibotenic acid induced neuronal degeneration. Neurosci 35:121-132.

Cortez S, McIntosh TK, Noble LJ (1989) Experimental fluid percussion brain injury: vascular distuption and neuronal glial alterations. Brain Res 482:271-282.

David S, Bouchard G, Tsatas O, Giftochristos N (1990) Macrophages can modify the nonpermissive nature of the adult mammalian central nervous system. Neuron 5:463-469.

del Zoppo GJ, Schmid-Schonbein GW, Mori E, Copeland BR, Chang CM (1991) Polymorphonuclear leukocytes occlude capillaries following middle cerebral artery occlusions and reperfusion in babbons. Stroke 22:1276-1283

Dietrich W, Alonso O, Busto R, Globus M, Ginsberg M (1994) Posttraumatic brain hypothermia reduces histopathological damage following concussive brain injury in the rat. Acta Neuropathol (Berl) $87: 250-258$

Dixon CE, Lyeth BG, Polvishock JT, Findling RI, Hamm RJ, Marmarou A, Young HF, Hayes RL (1987) A fluid percussion model of experimental brain injury in the rat: neurological, physiological, and histopathological characteristics. J Neurosurg 67:110-119.
Dusart I, Schwab ME (1994) Secondary cell death and the inflammatory reaction after dorsal hemisection of the rat spinal cord. Eur $\mathrm{J}$ Neurosci 6:712-724.

Flaris N, Densmore T, Molleston M, Hickey W (1993) Characterization of microglia and macrophages in the central nervous system of rats: definition of the differential expression of molecules using standard and novel monoclonal antibodies in normal CNS and in four models of parenchymal reaction. Glia 7:34-40.

Gallyas F, Wolff JR, Bottcher H, Zoborsky L (1980) $\Lambda$ reliable and sensitive method to localize terminal degeneration and lysosmes in the central nervous system. Stain Tech 55:299-306.

Garcia JH, Liu KF, Yoshida Y, Lian J, Chen S, del Zoppo GJ (1994) Influx of leukocytes and platelets in an evolving brain infarct (wistar rat). Am J Pathol 144:188-199.

Gotoh S, Itoh M, Fujii Y, Arai S, Sendo F (1986) Enhancement of a rat neutrophil-specific cell surface antigen by activation with phorbol myristate acetate and concanavalin A. J Immunol 137:643-650.

Giulian D, Chen J, Ingeman JE, George JK, Noponen M (1989) The role of mononuclear phagocytes in wound healing after traumatic injury to adult mammalian brain. J Neurosci 9:4416-4429.

Goodman J, Robertson C, Grossman R, Narayan R (1990) Elevation of tumor necrosis factor in head injury. J Neuroimmunol 30:213217.

Graham DI, Adams JH, Gennarelli TA (1993) Pathology of brain damage in head injury. In: Head injury, $3 \mathrm{~d}$ ed (Cooper E, ed), pp 91113. New York: Williams and Wilkins.

Hallenbeck JM, Dutka AM, Tanishima T, Kochanek PM, Kumaroo KK, Thompson CB, Obrenovitch TP, Contreras TJ (1986) Polymorphonuclear leukocyte accumulation in brain regions with low blood flow during the early postischemic period. Stroke 17:246-253.

Hama T, Miyamoto $M$, Tsukui $H$, Nishio $C$, Hatanaka $H$ (1989) Interleukin- 6 as a neurotrophic factor for promoting the survival of cultured basal forebrain cholinergic neurons from postnatal rats. Neurosei Lett 104.

Harlan JM (1985) Leukocyte-endothelial interactions. Blood 65:513525 .

Hicks R, Soares HD, Smith DH, McIntosh TK (1995) Temporal and spatial characterization of neuronal injury following lateral fluid-percussion brain injury in the rat. Acta Neuropathol (Berl), in press.

Hicks RR, Smith DH, Lowenstein DH, Saint-Marie R, McIntosh TK (1993) Mild experimental brain injury in the rat induces cognitive deficits associated with regional neuronal loss in the hippocampus. $\mathbf{J}$ Neurotrauma 10:405-414.

Holtz A, Nyström B, Gergin B, Olsson Y (1990) Neuropathological changes and neurological function after spinal cord compression in the rat. J Neurotrauma 7:155-167.

Horgan MJ, Wright SD, Malik AB (1990) Antibody against leukocyte integrin (CD18) prevents reperfusion-induced lung vascular injury. Am J Physiol 259:L315-L319.

Hovda DA, Yoshino A, Kawamata Y, Katayama Y, Becker DP (1991) Diffuse prolonged depression of cerebral oxidative metabolism following concussive brain injury in the rat: a cytochrome oxidase histochemistry study. Brain Res 567:1-10.

Kochanek PM, Hallenbeck JM (1992) Polymorphonuclear leukocytes and monocytes/macrophages in the pathogenesis of cerebral ischemia and stroke. Stroke 23:1367-1379.

Kochanek PM, Nemoto EM, Evans RW, Schoettle RJ (1990) Polymorphonuclear leukocytes, platelets, and lipid mediators in the pathogenesis of ischemic and traumatic central nervous system injury. In: Lipid mediators in ischemic brain damage and experimental epilepsy-new trends in lipid mediators research (Bazan NG, ed), pp 220240. Basel: Karger.

Lindholm D, Heumann R, Meyer M, Thoenen H (1987) Interleukin-1 regulates synthesis of nerve growth factor in non-neuronal cells of rat sciatic nerve. Nature 330:658-659.

Ling E, Wong W (1993) The origin and nature of ramified and amoegoid microglia: a historical review and current concepts. Glia 7:918.

Lowenstein D, Thomas M, Smith D, McIntosh T (1992) Selective vulnerability of dentate hilar neurons following traumatic brain injury: a potential mechanistic link between head trauma and disorders of the hippocampus. J Neurosci 12:4864-4853.

Lucchesi BR, Mullane KM (1986) Leukocyles and ischemia-induced myocardial injury. Annu Rev Pharmacol Toxicol 26:201-224.

Ma XL, Tsao PS, Lefer AM (1991) Antibody to CD-18 exerts endo- 
thelial and cardiac protective effects in myocardial ischemia and reperfusion. J Clin Invest 88:1237-1243.

Matsuo Y, Onodera H, Shiga Y, Nakamura M, Ninomiya M, Kihara T, Kogure K (1994) Correlation between myeloperoxidase-quantified neutrophil accumulation and ischemic brain injury in the rat: effects of neutrophil depletion. Stroke 25:1469-1475.

McClain C, Cohen D, Phillips R, Ott L, Young B (1991) Increased plasma and ventricular fluid interleukin 6 levels in patients with head injury. J Lab Clin Med 118:225-231.

McIntosh TK (1993) Novel pharmacologic therapies in the treatment of experimental traumatic brain injury: a review. J Neurotrauma 10: 215-261.

McIntosh TK, Vink R, Noble L, Yamakami I, Fernyak S, Soares HD, Faden AI (1989) Traumatic brain injury in the rat: characterization of a lateral fluid percussion model. Neuroscience 28:233-244.

Means ED, Anderson DK (1983) Neuronophagia by leukocytes in experimental spinal cord injury. J Neuropathol Exp Neurol 42:707-719.

Moreno-Flores MT, Bovolenta P, Nieto-Sampedro M (1993) Polymorphonuclear leukocytes in brain parenchyma after injury and their interaction with purified astrocytes in culture. Glia 7:146-157.

Mori T, Iijima N, Kitabatake K, Kosaka S (1990) Alpha-2-macroglobulin is an astroglia derived neurite promoting factor for cultured neurons from rat central nervous system. Brain Res 527:55-61.

Nadler JV, Evenson DA (1983) Use of excitatory amino acids to make axon-sparing lesions of the hypothalamus. Methods Enzymol 103: $393-400$.

O'Brien RF, Seton MP, Makarski JS, Center DM, Rounds S (1984) Thiourea causes endothelial cells in tissue culture to produce neutrophil chemoattratant activity. Am Rev Respir Dis 130:103-109.

Okiyama K, Rosenkrantz T, Smith D, Gennarelli T, McIntosh T (1994) (S)-Emopamil attenuates acute reduction in cerebral blood flow following experimental brain injury. J Neurotrauma 11:83-95.

Ott L, McClain CJ, Gillespie M, Young B (1994) Cytokines and metabolic dysfunction after severe head injury. J Neurotrauma 11:447472.

Persson L (1976) Cellular reactions to small cerebral stab wounds in the fronlal lobe. Virchows Arch 22:21-37.

Povlishock J (1986) Traumatically induced reactive axonal change without concomitant change in focally related neuronal somata and dendrites. Acta Neuropathol (Berl) 70:53-59,

Povlishock JT, Erb DE, Astruc J (1992) Axonal response to traumatic brain injury: reactive axonal change, deafferentation, and neuroplasticity. J Neurotrauma 9(Suppl 1):S189-S200.

Sahuquillo J, Vilalta J, Lamarca J, Rubio E, Rodriguez-Pazos M, Salva JA (1989) Diffuse axonal injury after sever head trauma. A clinicopathological study. Acta Neurochir 101:149-158.

Schmidt RH, Grady MS (1993) Regional patterns of blood-brain barricr brcakdown following central and lateral fluid percussion injury in rodents. J Neurotrauma 10:415-430.

Schoettle RJ, Kochanek PM, Magargee JM, Uhl MW, Nemoto EM (1990) Early polymorphonuclear leukocyte accumulation correlates with the development of post-traumatic cerebral edema in rats. J Neurotrauma 7:207-217.

Sloan DJ, Wood MJ, Charlton HM (1992) Leukocyte recruitment and inflammation in the CNS. Trends Neurosci 15:276-278.
Smith DH, Okiyama K, Thomas MJ, Claussen B, McIntosh TK (1991) Evaluation of memory dysfunction following experimental brain injury using the Morris Water Maze. J Neurotrauma 8:259-269.

Soares HD, Thomas M, Cloherty K, McIntosh TK (1992) Development of prolonged focal cerebral edema and regional cation changes following experimental brain injury in the rat. $J$ Neurochem $58: 1845-$ 1852.

Strich SJ (1956) Diffuse degeneration of the cerebral white matter in severe dementia following head injury. J Neurol Neurosurg Psychiatry 19:163-185.

Tanno H, Nockels RP, Pitts LH, Noble LJ (1992a) Breakdown of the blood brain barrier after fluid percussion injury in the rat. I. Distribution and time course of protein extravasation. $\mathbf{J}$ Neurotrauma 9:2132.

Tanno H, Nockels RP, Pitts LH, Noble LJ (1992b) Breakdown of the blood brain barrier after fluid percussion brain injury in the rat. 2 . Effect of hypoxia on permeability to plasma proteins. J Neurotrauma 9:335-347.

Tate RM, Repine JE (1983) Neutrophils and the adult respiratory distress syndrome. Am Rev Respir Dis 128:552-559.

Taupin V, Toulmond S, Serrano A, Benavides J, Zavala F (1993) Increase in IL-6, IL-1, and TNF levels in rat brain following traumatic lesion. Influence of pre- and post- traumatic treatment with Ro54864, a peripheral-type (p site) benzodiazepine ligand. J Neuroimmunol 42 : $177-185$

Tonnesen MG, Worthen GS, Johnston RB (1988) Neutrophil emigration, activation, and tissue damage. In: The molecular and cellular biology of wound repair (Clark RAF, Hensen PM, eds), pp 149-184. New York: Plenum.

Uhl MW, Biagas KV, Grundl PD, Barmada MA, Schiding JK, Nemoto EM, Kochanek PM (1994) Effects of neutropenia on edema, histology, and cerebral blood flow after traumatic brain injury in rats. $J$ Neurotrauma 11:303-315.

Vink R, McIntosh T, Yamakami I, Faden A (1988) Phosphorous 31 NMR characterization of graded traumatic brain injury in rats. Magn Reson Med 6:37-48.

Wedmore CV, Williams JT (1981) Control of vascular permeability by polymorphonuclear leukocytes in inflammation. Nature 289:646-650.

$\mathrm{Xu}$ J, Hsu CY, Liu TH (1990) Leukotriene $\mathrm{B}_{4}$ release and polymorphonuclear cell infiltration in spinal cord injuiry. J Neurochem 55: 907-912.

Yamakami I, McIntosh TK (1991) Alterations in regional cerebral blood flow following brain injury in the rat. J Cereb Blood Flow Metab 11:655-660.

Yamazaki T, Seko Y, Tamatani T, Miyasaka M, Yagita H, Okumura K, Nagai R, Yazaki Y (1993) Expression of intercellular adhesion molecule-1 in rat heart with ischemia/reperfusion and limitation of infarct size by treatment with antibodies against cell adhesion molecules. Am J Pathol 143:410-108.

Yoshino A, Hovda D, Kawamata T, Katayama Y, Becker D (1991) Dynamic changes in local cerebral glucose utilization following cerebral concussion in rats: evidence of a hyper- and subsequent hypometabolic state. Brain Res 561:106-119.

Zhuang J, Shackford SR, Schmoker JD, Anderson ML (1993) The association of leukocytes with secondary brain injury. J Trauma 35: $415-422$. 